\title{
Pathways to Smoking and Snus Use Cessation - Is Spontaneous Quitting Underrated?
}

\author{
Mats Toftgård ${ }^{*}, 1$, Hans Gilljam ${ }^{2}$ and Tanja Tomson ${ }^{2}$
}

\author{
Karolinska Institutet, Department of Public Health Sciences, ${ }^{1}$ Division of Applied Public Health, ${ }^{2}$ Division of Social \\ Medicine, Stockholm, Sweden
}

\begin{abstract}
Aim: To investigate to what extent smokers and snus users in Sweden consider and plan their quit attempts in advance, and to assess if spontaneity is associated with success.

Methods: A sample of 5999 Swedish men and women between 16 and 80 years were interviewed via telephone about current and former smoking and snus use and their latest quit attempts.

Results: Among 2272 ex-smokers and current smokers who had ever made a serious quit attempt 48\% reported to not having planned their latest attempt in advance. Furthermore, $40 \%$ reported to not even having considered giving up smoking before they actually made the attempt. Of 809 former and current snus users $48 \%$ did not plan, and $44 \%$ did not consider quitting in advance. Smokers and ex-smokers were more likely to remain smoke-free for at least six months if the attempt was unplanned (sex and age adjusted $\mathrm{OR}=2.6 ; 95 \% \mathrm{CI}=1.7-3.8$ ). When dividing the smoking quit attempts into considered versus not considered the advantage of the spontaneous attempts remained (adjusted $\mathrm{OR}=1.9 ; \mathrm{CI}=1.3-2.9$ ). The corresponding analyses of snus use quitting showed similar advantages for the unplanned and the not considered quit attempts.

Conclusions: In Sweden, a considerable proportion of the attempts to quit smoking, as well as to quit using snus, are made without prior consideration or planning. Spontaneous quit attempts appear to have a greater chance of long-term success than those preceded by consideration or planning.
\end{abstract}

Keywords: Smoking cessation, smokeless tobacco, unplanned, Sweden.

\section{INTRODUCTION}

Our knowledge about the process of stopping smoking is extensive but it stems mostly from clinical trials involving pharmaceuticals [1]. Most smokers do not seek formal cessation help and knowledge about factors that impact smoking cessation among self-quitters is limited $[2,3]$. In particular, the occurrence and significance of planning quit attempts has not been thoroughly made clear, being more or less implied in aided smoking cessation. The situation is even more uncertain regarding smokeless tobacco use cessation [4]. In Sweden 2006, 21\% of the men and 4\% of the women were daily snus (Swedish smokeless tobacco) users compared to a prevalence of daily cigarette smoking of $13 \%$ among men and $15 \%$ among women [5]. According to a population survey in Northern Sweden, seven out of ten smokers and four out of ten snus users want to quit [6]. Since the 1980's the dominating behavioural change theory in the field of smoking cessation has been the Transtheoretical model [7]. According to this model an intention to quit will progress to complete cessation through a number of defined stages: Precontemplation (not considering change), Contemplation (considering change), Preparation (planning change), Action (first six months after change) and Maintenance (more than six months after change). However, the relevance of the Transtheoretical model

\footnotetext{
*Address correspondence to this author at the Karolinska Institutet, Department of Public Health Sciences, Division of Applied Public Health, P.O. Box 17070, SE-104 62 Stockholm, Sweden; Tel: +46 8524875 53; E-mail: mats.toftgard@ki.se
}

has been challenged on several grounds, both as to descriptive purposes and as a guide for aided smoking cessation [8]. In surveys from Canada, the United Kingdom and the United States, $37-52 \%$ of the smokers and ex-smokers reported to having quit spontaneously without any preplanning [9-12]. In other words, these smokers quit without passing the Preparation stage of the model. Furthermore, these unplanned quit attempts appeared to be significantly more likely to be successful than those that were planned in advance. The Contemplation stage has to our knowledge not been challenged in the same manner previously.

The aim of this study was to investigate to what extent smokers and snus users in Sweden consider and plan their quit attempts in advance, and to assess if the presence or absence of prior consideration and planning is associated with longterm success.

\section{METHODS}

An extended set of questions on tobacco use were added to the monthly surveys with main focus on alcohol consumption during March to June 2006 carried out by the market research agency Temo, commissioned by Centre for Social Research on Alcohol and Drugs (SoRAD) at Stockholm University. The samples were made by means of Temo's standard method for telephone-based, representative sampling of the population using its comprehensive register of household telephone numbers with compensation for secret numbers. The response rate in the surveys amounted to 50 percent. A total of 5999 respondents of Swedish-speaking men and women between 16 
and 80 years of age were interviewed. Anonymity was guaranteed. No ethical problems were identified.

In order to increase representativeness Temo constructed a weight variable consisting of two components; an adjustment for differences in sample probabilities due to household size and post stratification on age, sex and region. When the weights were applied the number of respondents decreased somewhat to 5988 due to rounding errors. The proportion of women decreased from $53.1 \%$ to $50.3 \%$. Where applicable the findings presented here come from weighted data.

The question defining smoking prevalence was: "During the last 30 days, have you been smoking cigarettes daily?" Those who reported to be daily smokers were asked: "During the last 30 days, on average, how many cigarettes have you smoked a day?" Respondents not being current daily cigarette smokers were asked: "Have you ever smoked daily?" Exsmokers and current smokers were asked: "When did you start smoking daily?" Ex-smokers and current smokers who had ever made a serious quit attempt were asked: "When did you quit smoking?" and "When did you quit smoking the last time?" respectively. Respondents to the latter question were asked: "For how long were you smoke-free the last time?". On the basis of this we constructed an outcome measure, where success was defined as being smoke-free for at least six months. In line with the British study by West [10] exsmokers and current smokers who had ever made a serious quit attempt were asked: "Which of these statements best describes how your most recent quit attempt started?" The response options were: " 1 . I did not plan the quit attempt in advance, I just quit; 2 . I planned the quit attempt earlier the same day; 3 . I planned the quit attempt one day in advance; 4. I planned the quit attempt 2-30 days in advance; 5. I planned the quit attempt more than a month in advance; 6 . Other; 7.
Don't know" The data presented are categorised into "Unplanned" (option 1), "Planned" (option 2-5) and "Other / Don't know" (option 6-7). This question could be considered to reflect the preparation stage in the Transtheoretical model. To further investigate the relations between the stages of change and quitting, we also asked the following question which would then reflect the contemplation stage: "How long before your most recent quit attempt did you start considering quitting smoking?" Corresponding to all of the smoking related questions above, the same were asked about snus use.

Chi square tests were used to detect differences between sexes, age groups and 'time since quit attempt' groups in proportions of spontaneous quitting. Odds ratios comparing success rates of spontaneous versus non spontaneous smoking and snus use quit attempts, with adjustments for sex and age, were calculated by means of multiple logistic regression analysis.

\section{RESULTS}

Twelve percent of the men and $14.9 \%$ of the women were daily cigarette smokers. $22.4 \%$ of the men and $3.2 \%$ of the women were daily users of snus. $2.5 \%$ of the men and $0.3 \%$ of the women reported daily use of both cigarettes and snus. The average number of cigarettes smoked per day among daily smokers was 11.8 , and among daily snus users the average number of cans of snus consumed per week was 3.8. Of the respondents $29.1 \%$ reported to be ex-smokers and $8.6 \%$ were ex-snus users. In total 2532 reported to have ever smoked daily, of these $89.7 \%$ had ever made a serious quit attempt. Of the 1249 respondents who had ever used snus daily $64.8 \%$ had ever made a serious quit attempt.

Among the 2272 ex-smokers and current smokers who had ever made a serious quit attempt $48.0 \%$ reported to not having

Table 1. Percentages (Numbers) of Attempts to Quit Smoking and Snus Use, Divided into Planned vs Unplanned and Considered vs Not Considered, Analysed by Sex, Age and Time Since Quit Attempt. Data Weighted with Respect to Household Size, Age, Sex and Region

\begin{tabular}{|c|c|c|c|c|c|c|c|c|c|}
\hline \multirow{2}{*}{ Attempts to Quit } & \multicolumn{2}{|c|}{ Sex } & \multicolumn{3}{|c|}{ Age (Years) } & \multicolumn{3}{|c|}{ Time Since Attempt (Years) } & \multirow{2}{*}{ Total } \\
\hline & Male & Female & $16-34$ & $35-54$ & $55-80$ & $0-5$ & $>5$ & Missing & \\
\hline \multicolumn{10}{|l|}{ Smoking $(n=2272)$} \\
\hline Unplanned & $52.6(593)^{*}$ & $43.5(498)$ & $49.6(210) \dagger$ & $45.5(402)$ & $49.6(479)$ & $42.2(300) \div$ & $51.1(751)$ & $43.5(40)$ & $48.0(1091)$ \\
\hline Planned & $41.4(467)$ & $50.2(575)$ & $45.2(191)$ & $50.0(442)$ & $42.4(409)$ & $55.0(391)$ & $42.1(619)$ & $34.8(32)$ & $45.9(1042)$ \\
\hline Other/Don't know & $5.9(67)$ & $6.3(72)$ & $5.2(22)$ & $4.5(40)$ & $8.0(77)$ & $2.8(20)$ & $6.7(99)$ & $21.7(20)$ & $6.1(139)$ \\
\hline Not considered & $43.4(489)^{*}$ & $37.1(425)$ & $39.2(166) \dagger$ & $38.8(343)$ & $42.0(405)$ & $31.7(226) \div$ & $44.6(655)$ & $35.9(33)$ & $40.2(914)$ \\
\hline Considered & $46.4(523)$ & $51.9(594)$ & $53.2(225)$ & $50.5(446)$ & $46.2(446)$ & $60.3(429)$ & $44.5(653)$ & $38.0(35)$ & $49.2(1117)$ \\
\hline Other/Don't know & $10.2(115)$ & $11.0(126)$ & $7.6(32)$ & $10.7(95)$ & $11.8(114)$ & $8.0(57)$ & $10.9(160)$ & $26.1(24)$ & $10.6(241)$ \\
\hline \multicolumn{10}{|l|}{ Snus Use $(n=809)$} \\
\hline Unplanned & $49.3(333)$ & $42.9(57)$ & $44.5(118) \dagger$ & $48.6(176)$ & $52.7(96)$ & $42.0(152) \neq$ & $55.0(209)$ & $43.3(29)$ & $48.2(390)$ \\
\hline Planned & $45.9(310)$ & $47.4(63)$ & $52.5(139)$ & $45.9(166)$ & $37.4(68)$ & $56.4(204)$ & $37.9(144)$ & $37.3(25)$ & $46.0(373)$ \\
\hline Other/Don't know & $4.9(33)$ & $9.8(13)$ & $3.0(8)$ & $5.5(20)$ & $9.9(18)$ & $1.7(6)$ & $7.1(27)$ & $19.4(13)$ & $5.7(46)$ \\
\hline Not considered & $45.0(304)^{*}$ & $38.3(51)$ & $42.6(113)$ & $42.0(152)$ & $49.5(90)$ & $38.4(139) \$$ & $49.7(189)$ & $40.3(27)$ & $43.9(355)$ \\
\hline Considered & $46.9(317)$ & $45.1(60)$ & $49.1(130)$ & $48.6(176)$ & $38.8(71)$ & $55.0(199)$ & $41.8(159)$ & $28.4(19)$ & $46.6(377)$ \\
\hline Other/Don't know & $8.1(55)$ & $16.5(22)$ & $8.3(22)$ & $9.4(34)$ & $11.5(21)$ & $6.6(24)$ & $8.4(32)$ & $31.3(21)$ & $9.5(77)$ \\
\hline
\end{tabular}

*Significant difference between sexes $(\mathrm{p}<0.05)$.

'Significant difference between age groups $(\mathrm{p}<0.05)$.

'Significant difference between 'Time since attempt' groups $(\mathrm{p}<0.05)$. 
planned their latest attempt in advance, not even the same day (Table 1). Of the 1042 reporting to have planned their latest smoking quit attempt $13.7 \%$ started planning earlier the same day, $8.9 \%$ one day in advance, $37.3 \%$ two to thirty days in advance and $40.2 \%$ more than a month in advance (not in table). Furthermore, $40.2 \%$ of the 2272 ex-smokers and current smokers did not consider giving up smoking before they actually made the attempt. Regarding the attempts to quit using snus, the pattern was quite similar. Of 809 former and current snus users $48.2 \%$ did not plan and $43.9 \%$ did not consider quitting in advance. In general males were quitting without planning or consideration in advance to a greater extent than females. Smokers and snus users aged 55-80 were slightly more likely to quit without prior planning or consideration than the younger. Quit attempts made more than five years ago were more likely to be reported as spontaneous than those made more recently, indicating that recall bias was a significant factor.

Table 2 presents comparisons of the outcome of smoking and snus use quit attempts that were planned or unplanned and considered or not considered in advance. Since we defined success as abstinence from smoking or snus use for at least six months the analyses were restricted to attempts made at least six months previously. To reduce potential recall bias we also excluded attempts that were made more than five years previously. Both current and former smokers and snus users were included in the analyses, which explains the overall high success rates.

Smokers and ex-smokers who made their last quit attempt between six months and five years ago were considerably more likely to remain smoke-free for at least six months if the attempt was unplanned. Of the unplanned smoking quit attempts $79.1 \%$ were successful compared to $58.5 \%$ of the planned ones. The sex and age adjusted odds ratio was 2.6, with a $95 \%$ confidence interval of 1.7 to 3.8 . When dividing the smoking quit attempts into considered and not considered the advantage of the spontaneous attempts remained (adjusted odds ratio $1.9,1.3$ to 2.9 ). The corresponding analyses of snus use quit attempts showed that also in this respect snus users did not differ from smokers. Unplanned snus use quit attempts were significantly more successful than planned (adjusted odds ratio $2.5,1.3$ to 4.6 ), and attempts not considered in advance succeeded to a higher degree than those considered in advance (adjusted odds ratio 2.0, 1.3 to 3.8).

\section{DISCUSSION}

The results of our study indicate that in Sweden nearly half of the attempts to quit smoking, as well as to quit using snus, are made without any preplanning. Despite the notably low prevalence of daily smoking in Sweden and other cultural differences, the proportion of unplanned smoking quit attempts is similar to those reported from Canada, England and the U.S. [9-12]. Furthermore, in our survey four out of ten smokers and snus users claimed to not even having considered quitting in advance. Thus, our results suggest that a considerable proportion of the smoking and snus use quit attempts are performed without passing the stages of contemplation and preparation in the Transtheoretical model, presupposing that prior consideration and planning are fundamental components of these stages. In other words, these attempts could be described as if the smoker or snus user suddenly got an impulse to quit and immediately went into action. According to other studies this impulse would typically be a health related event such as an asthma attack, but even quite trivial events such as a temporary shortage of cigarettes can be triggers for successful spontaneous quitting $[9,12]$.

The absence of not only planning but even consideration of quitting before the quit attempt in such a large proportion of the smokers and snus users might seem hard to grasp. It is possible that the attempt is preceded by a subconscious desire to quit, or as has been proposed, that a sufficient level of "motivational tension" have been built up [10]; a state of mind not being perceived by the individual as thoughts of quitting. Moreover, the proportion of unplanned and not considered attempts is most likely overestimated due to recall bias. This notion is supported in our data by a correlation between spontaneity and recency - attempts made a long time ago are more likely to be reported as unplanned and not considered than the more recent ones. To remember the thought process preceding a quit attempt made several years ago might understandably be difficult. Furthermore, the response rate of the survey was relatively low, which may cause sampling bias. This was however compensated for by means of weighting.

Table 2. Success of Quit Attempts in Relation to Prior Planning and Consideration. Former and Current Smokers and Snus Users who Made their Last Attempt between 6 Months and 5 Years Previously. Unweighted Data

\begin{tabular}{|l|c|c|c|}
\hline \multicolumn{1}{|c|}{ Attempts to Quit } & Lasted $\geq \mathbf{6}$ Months \% (n/N) & Crude OR (95\% CI) & OR Adjusted for Sex and Age (95\% CI) \\
\hline \hline Smoking & $79.1(197 / 249)$ & $2.7(1.8-3.9)$ & $2.6(1.7-3.8)$ \\
\hline Unplanned & $58.5(182 / 311)$ & 1.0 & 1.0 \\
\hline Planned & $77.4(151 / 195)$ & $2.0(1.3-2.9)$ & $1.9(1.3-2.9)$ \\
\hline Not considered & $63.5(214 / 337)$ & 1.0 & 1.0 \\
\hline Considered & & & $2.5(1.3-4.6)$ \\
\hline Snus Use & $82.2(88 / 107)$ & 1.0 & 1.0 \\
\hline Unplanned & $64.5(89 / 138)$ & $1.9(1.0-3.5)$ & $2.0(1.1-3.8)$ \\
\hline Planned & $80.6(83 / 103)$ & 1.0 & 1.0 \\
\hline Not considered & $68.5(89 / 130)$ & & \\
\hline Considered & &
\end{tabular}


The chance of long-term success appears to be greater for the spontaneous smoking and snus use quit attempts. The lack of potentially confounding variables in the data set is however a significant limitation of this study. It is plausible that the difference in outcome to some extent could be explained by a difference of personal characteristics between individuals who consider and plan the attempt in advance and those who do not. In particular, factors known to predict abstinence such as nicotine dependence and self-efficacy may differ $[13,14]$. A person with strong beliefs about his or her capacity to change behavior might be more inclined to act on impulse, whereas the less confident person's reaction might be to start contemplating and planning a quit attempt. In the study of U.S. smokers and ex-smokers, unplanned quitting was more common among those who were less dependent, and controlling for dependence moderated the effect of spontaneity on success. Still the unplanned attempts had more than twice the odds of being successful [11]. Furthermore, it is widely accepted that use of cessation aids increases the likelihood of success [15]. Not surprisingly, it has been shown that it is less common that unplanned attempts are aided by use of behavioural support and pharmacotherapy [12]. Thus it is reasonable to believe that nicotine dependence and use of cessation aids to some extent would counterbalance each other as confounders. In summary, it would be valuable to further investigate potential confounders in future studies, preferably with prospective designs if possible.

Snus and cigarettes are of course closely related in the sense that they both are delivery systems for nicotine, and they are similarly addictive [16]. Nevertheless there are considerable differences. Snus use is clearly less harmful than cigarette smoking [17]. The proportion of snus users who want to quit is smaller [6], which is reflected by lower cessation rates [18]. This is also supported by our data, a substantially smaller proportion of the ever-snus users compared to the ever-smokers reported to have ever made a quit attempt. Yet our results show a striking similarity between snus use and smoking regarding both the proportion of unplanned and not considered quit attempts and the advantage in outcome of these attempts over the considered and planned ones.

In conclusion, the importance of planning may be overstated in the prevailing tobacco cessation recommendations, with the caveat that we may be talking about different populations. The fact that many smokers and snus users seems to be more likely to succeed when quitting spontaneously might be a basis for health professionals and quitline counsellors to encourage their clients to act on the impulse that made them seek help, rather than telling them to make up a plan to quit a few weeks later. This could also be an argument for repeated anti tobacco campaigns, promoting impulse driven quit attempts. Providing rapid and easy access to behavioural support and pharmacotherapy for spontaneous quitters could further improve the chances of success.

\section{ACKNOWLEDGEMENTS}

This study was funded by the Stockholm County Council. We would like to thank Dr. Rosaria Galanti and Prof. Scott Leischow for their valuable suggestions for improving the manuscript.

\section{REFERENCES}

[1] Fiore MC, Jaen CR, Baker TB, et al. Treating tobacco use and dependence: Update. Clinical Practice Guideline. Rockville, MD: U.S. Department of Health and Human Services. Public Health Service 2008.

[2] Gross B, Brose L, Schumann A, et al. Reasons for not using smoking cessation aids. BMC Public Health 2008; 8: 129.

[3] Sieminska A, Buczkowski K, Jassem E, Lewandowska K, Ucinska R, Chelminska M. Patterns of motivations and ways of quitting smoking among Polish smokers: a questionnaire study. BMC Public Health 2008; 8: 274.

[4] Ebbert JO, Montori V, Vickers KS, Erwin PC, Dale LC, Stead LF. Interventions for smokeless tobacco use cessation. Cochrane Database Syst Rev 2007; 4: CD004306.

[5] Wadman C, Boström G, Karlsson A-S. Health On Equal Terms? Results from the 2006 Swedish National Public Health Survey. Report A 2008:01, Swedish National Institute of Public Health, 2008. Available at: http://www.fhi.se/PageFiles/4351/A2008_1_health\%2 0on\%20equal\%20terms.pdf [Accessed Sept 2009].

[6] Fröling H, Janlert U, Malker B, Sandberg K. Life and Health in Northern Sweden 2003 [In Swedish: Liv och Hälsa i Norrland 2003], Report 2003:1. County Councils of Jämtland, Västerbotten, Västernorrland and Norrbotten, 2004. Available at: http://www.nll.se/u pload/IB/lg/sekr/fh/rapp/Norrland2003.pdf [Accessed Sept 2009].

[7] Prochaska JO, Velicer WF. The transtheoretical model of health behavior change. Am J Health Promot 1997; 12: 38-48.

[8] West R. Time for a change: putting the Transtheoretical (Stages of Change) Model to rest. Addiction 2005; 100: 1036-9.

[9] Larabie LC. To what extent do smokers plan quit attempts? Tob Control 2005; 14: 425-8.

[10] West R, Sohal T. "Catastrophic" pathways to smoking cessation: findings from national survey. BMJ 2006; 332: 458-60.

[11] Ferguson SG, Shiffman S, Gitchell JG, Sembower MA, West R. Unplanned quit attempts--results from a U.S. sample of smokers and ex-smokers. Nicotine Tob Res 2009; 11: 827-32.

[12] Murray RL, Lewis SA, Coleman T, Britton J, McNeill A. Unplanned attempts to quit smoking: missed opportunities for health promotion? Addiction 2009; 104: 1901-9.

[13] Hyland A, Borland R, Li Q, et al. Individual-level predictors of cessation behaviours among participants in the International Tobacco Control (ITC) Four Country Survey. Tob Control 2006; 15: iii83iii94.

[14] Gwaltney CJ, Metrik J, Kahler CW, Shiffman S. Self-efficacy and smoking cessation: a meta-analysis. Psychol Addict Behav 2009; 23: 56-66.

[15] West R, McNeill A, Raw M. Smoking cessation guidelines for health professionals: an update. Thorax 2000; 55: 987-99.

[16] Holm H, Jarvis MJ, Russell MA, Feyerabend C. Nicotine intake and dependence in Swedish snuff takers. Psychopharmacology 1992; 108: 507-11.

[17] Levy DT, Mumford EA, Cummings KM, et al. The relative risks of a low-nitrosamine smokeless tobacco product compared with smoking cigarettes: estimates of a panel of experts. Cancer Epidemiol Biomarkers Prev 2004; 13: 2035-42.

[18] Furberg H, Lichtenstein P, Pedersen NL, Bulik C, Sullivan PF. Cigarettes and oral snuff use in Sweden: prevalence and transitions. Addiction 2006; 101: 1509-15.

This is an open access article licensed under the terms of the Creative Commons Attribution Non-Commercial License (http://creativecommons.org/licenses/by$\mathrm{nc} / 3.0 /$ ) which permits unrestricted, non-commercial use, distribution and reproduction in any medium, provided the work is properly cited. 